\title{
Cardiothoracic surgical critical care certification: A future of distinction
}

\author{
Hisham M. F. Sherif, MD, FACS, FICS, FACC, FAHA
}

\begin{abstract}
Cardiothoracic surgical critical care has emerged as a unique area of practice within cardiothoracic surgery. Leaders of multidisciplinary, high-performing teams are uniquely educated, trained, and skilled surgeons. Certification in this specialty by the American Board of Thoracic Surgery is a recognition of their distinction. A foundational framework is proposed toward this goal. (J Thorac Cardiovasc Surg 2016;152:34-6)
\end{abstract}

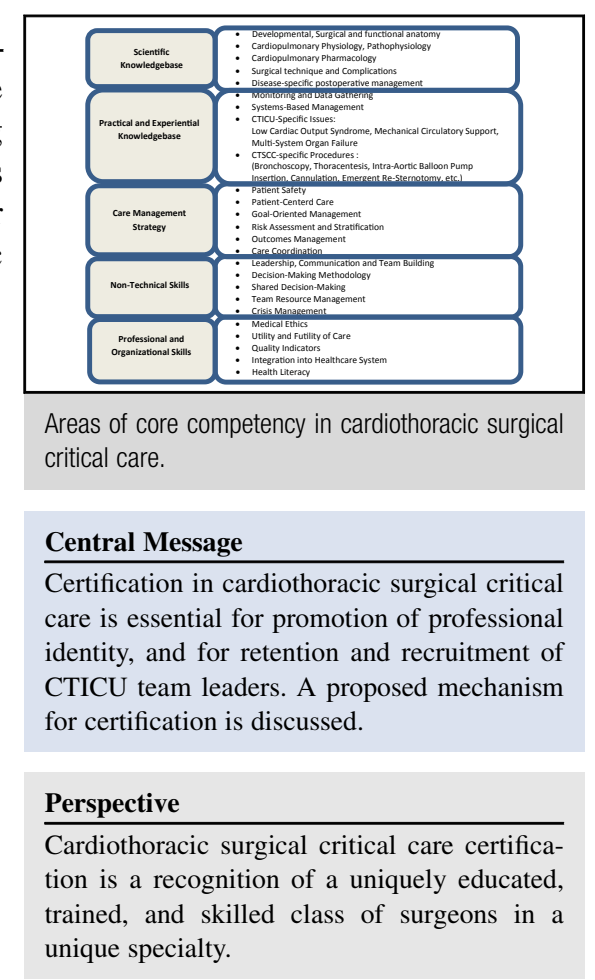

See Editorial Commentary page 37.
In the October 2015 issue of the Journal, ${ }^{1}$ Dr Katz provides a timely reminder of the continuing evolution of the scope and area of practice of cardiothoracic surgical critical care (CTSCC). Cardiothoracic surgical intensive care units (CTICUs) remain active areas of complex, critical, and high-risk surgical practice. The patient population is predominantly postoperative (and occasionally preoperative) surgical patients. The procedures that these patients undergo (conventional open surgical, minimally invasive, video- or robot-assisted, or even at the bedside) are highly specialized, technologically advanced, and highly skilled

From Christiana Care Cardiac Surgery, Newark, Del.

Received for publication Oct 13, 2015; revisions received Jan 4, 2016; accepted for publication Jan 12, 2016; available ahead of print Feb 10, 2016.

Address for reprints: Hisham M. F. Sherif, MD, FACS, FICS, FACC, FAHA, Christiana Care Cardiac Surgery, 4755 Ogletown-Stanton Rd, Ste 1E50, Newark, DE 19718 (E-mail: hsherif@christianacare.org). $0022-5223 / \$ 36.00$

Copyright $($ C 2016 by The American Association for Thoracic Surgery http://dx.doi.org/10.1016/j.jtcvs.2016.01.019 surgical procedures involving the vital organs within the chest.

This unique area of surgical practice also involves efforts by members of several other healthcare disciplines and specialties, all working together as a single high-performing team toward the successful recovery of the patient's cardiopulmonary function, in the context of an improved duration and quality of life. ${ }^{2}$ This multidisciplinary team is led by a uniquely educated, trained, and skilled surgeon with unparalleled experience in this specific area of surgical practice. ${ }^{3,4}$ Heretofore, the lack of uniform standards for the certification of such surgeon leaders of the CTICU teams is a reason for the current situation, with a heterogenous mix of nonsurgeon clinicians (certified by other boards, such as anesthesiology, critical care medicine, and others) assuming leadership roles in CTICUs, with varying degrees of success. ${ }^{5-7}$ This status quo calls our attention to the statement on principles set forth by the American College of Surgeons, ${ }^{8}$ as well as the mission statement 


\section{Abbreviation and Acronyms}

AATS $=$ American Association for Thoracic Surgeons

ABTS = American Board of Thoracic Surgery

CTICU $=$ cardiothoracic surgical intensive care unit CTS $=$ cardiothoracic surgery

$\mathrm{CTSCC}=$ cardiothoracic surgical critical care

from the American Board of Thoracic Surgery (ABTS). ${ }^{9}$ Both of these professional organizations stipulate that "the surgeon is responsible for the patient's safety throughout the preoperative, operative, and postoperative period," including critical care management. ${ }^{10,11}$

The uniqueness of managing such complex patients in the high-risk environment of the CTICU has long been recognized by the American Association of Critical Care Nurses, which has introduced a separate certification (cardiac surgical certification) for critical care nurses who have spent a minimum number of hours providing care for cardiothoracic surgery (CTS) patients. ${ }^{12}$ Of note, the absence of a formal, comprehensive didactic or clinical educational and/or training curriculum for such nurses has been addressed in Europe recently through the establishment of a common educational platform across the continent for the professional development of cardiovascular nurses in each member country. ${ }^{13}$
In addition, candidates for the Surgical Critical Care Program Directors Society's surgical critical care fellowship have been required to spend a brief rotation in a cardiothoracic surgical critical care unit, where they learn from cardiothoracic surgeons the unique, specific, and complex details of this area of practice. ${ }^{14}$ Of note, at present, those cardiothoracic surgeons themselves cannot be certified in this same area by the board governing their specialty. ${ }^{15,16}$

In light of this situation, the ABTS has maintained its public disapproval with the exclusion of fully trained cardiothoracic surgeons from certification in CTSCC. ${ }^{17}$ This commendable position reflects the dissatisfaction with the status quo within the global cardiothoracic surgical community ${ }^{18,19}$ (personal communication, Andreas Markewitz, MD, PhD, May 2014 and Jerry Baum, MD, PhD, November 2015). Recent efforts and initiatives by the ABTS and the American Association for Thoracic Surgeons (AATS) reflect the desire for change and shared vision within the CTS global community of an established robust mechanism for the certification of fully educated and trained cardiothoracic surgeons in this subspecialty. ${ }^{15,20}$

According to Dannemiller and Jacobs, ${ }^{21}$ dissatisfaction with the status quo and a vision for the future are 2 of the 3 essential elements for effecting positive organizational change. The third element is the establishment and implementation of concrete steps toward realizing this goal. The combined effect of these 3 forces is sufficient to

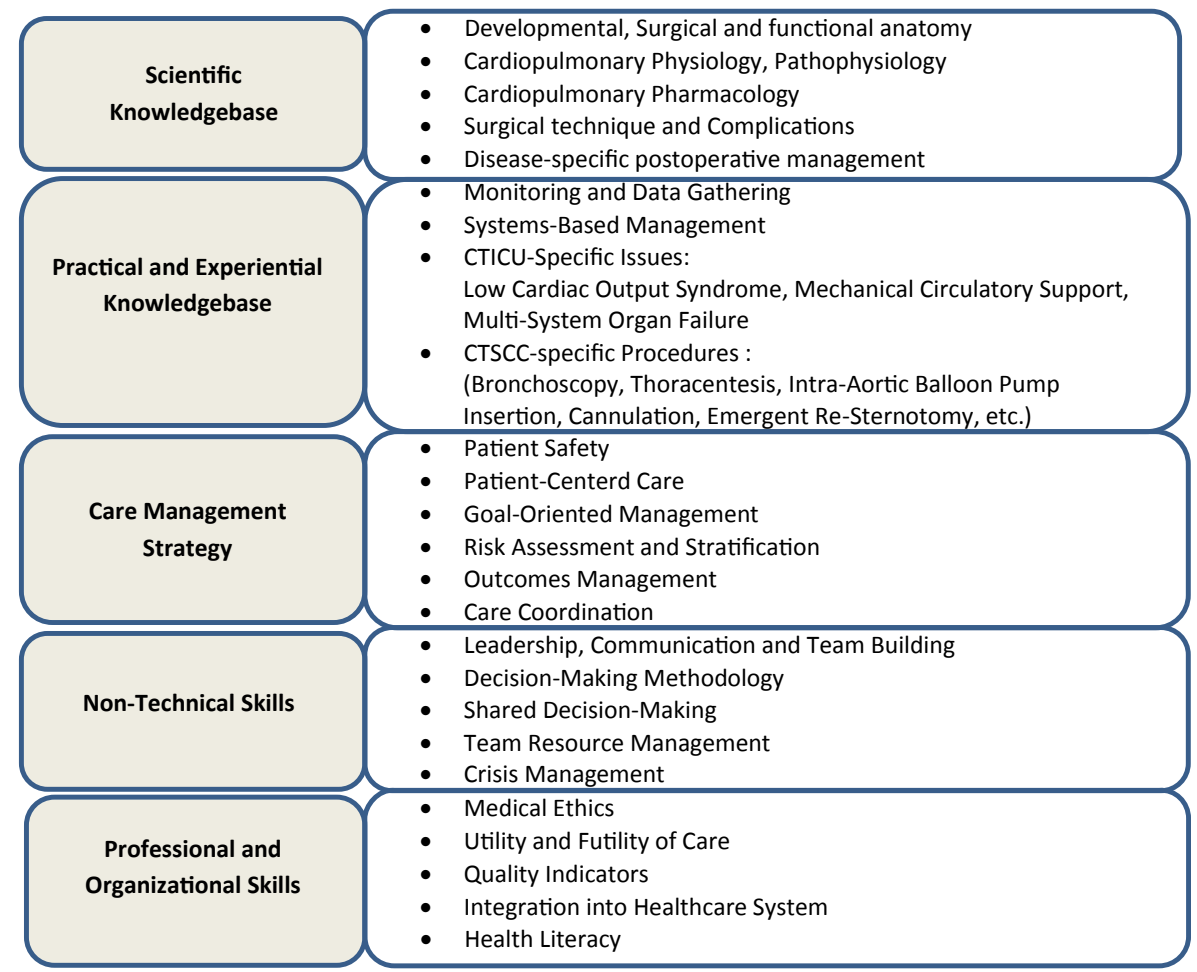

FIGURE 1. Suggested list of core competencies in the practice of cardiothoracic surgical critical care. CTICU, Cardiothoracic surgical intensive care unit; CTSCC, cardiothoracic surgical critical care. 
overcome the resistance or cost of change. The CTS global community looks forward to the emergence and implementation of a foundational framework from the governing organizations of the specialty, such as the ABTS, that outlines the specific areas of core competency essential for safe and effective practice of CTSCC (Figure 1) and can be adapted for application in different countries to fit with the local educational and regulatory environments.

This foundational framework, which may take the form of a "position statement," should provide the platform for standardized educational, training, experiential, ${ }^{22}$ skill, and professional criteria for assessment of proficiency, either by fulfilling these requirements or by passing an examination. This framework also should provide mechanisms through which prospective candidates can attain proficiency in each core competency area, whether by completing a CTS residency or fellowship or by completing short, dedicated courses organized by the CTS parent organizations (such as the AATS patient safety or nonoperative technical surgical skills course). Precedents for such requirements abound, including courses for transcatheter aortic valve replacement and mechanical circulatory support. A specific number of continuing medical education hours may be required to reflect the completion of these educational activities. A logbook of a specific number, case mix, and CTICU procedures may be required as well.

In conclusion, the landscape of CTS and its subspecialties is changing rapidly, thanks to the growing transdisciplinary exchange of knowledge and technology. However, the fundamental mission of professional organizations remains the same: to define the requirements for education, training, and skills to practice a specific area of medicine, and to determine the competency of candidates to safely practice. Therefore, it becomes imperative for the governing organizations of any given specialty to adopt novel and adaptable mechanisms for certification that evolve with the specialty and to increase the number of uniquely trained and credentialed surgeons in this specific area of practice. This should support the career pathway chosen by such surgeons and have an advantageous impact on recruitment, retention, and CTICU staffing within the medical marketplace. Thus, these governing organizations can remain true to their mission of promoting professionalism, scientific knowledge, and integrity, while safeguarding professional identity and the interests of its constituent members.

\section{Conflict of Interest Statement}

Authors have nothing to disclose with regard to commercial support.

The author remains appreciative of the feedback and discussions from cardiothoracic surgeons in the US, Canada, the United Kingdom, and Germany regarding this topic. The author also would like to thank the CTICU nurses Ms K. Romanowicz, Ms
K. Clark, and Ms S. Fetters for their invaluable input and perspective.

\section{References}

1. Katz NM. Meeting the expanded challenges of the cardiothoracic intensive care unit. J Thorac Cardiovasc Surg. 2015;150:777-8.

2. Sherif HM. Cardiothoracic surgical critical care: principles, goals and direction. Int J Surg. 2012;10:111-4.

3. Katz NM. The evolution of cardiothoracic critical care. J Thorac Cardiovasc Surg. 2011;141:3-6.

4. Katz NM. The emerging specialty of cardiothoracic surgical critical care: the leadership role of cardiothoracic surgeons on the multidisciplinary team. $J$ Thorac Cardiovasc Surg. 2007;134:1109-11.

5. Whitson BA, D'Cunha J. The thoracic surgical intensivist: the best critical care doctor for our thoracic surgical patients. Semin Thorac Cardiovasc Surg. 2011; 23:12-3.

6. Sherif HM. After-hours coverage of cardiothoracic critical care units by nonsurgeons: process and value issues. Eur J Cardiothorac Surg. 2014;46:507.

7. Arora RC. Canadian Critical Care Forum. Plenary debate: Who should run the (CV) surgical ICU. Available at: http://www.criticalcarecanada.com/ presentations/2013/i_prefer_surgeons.pdf. Accessed October 15, 2015.

8. American College of Surgeons. Statements on principles. Available at: https:// www.facs.org/about-acs/statements/stonprin. Accessed November 12, 2015.

9. American Board of Thoracic Surgery. ABTS mission statement. Available at: www.abts.org/root/home/mission-statement.aspx. Accessed November 12, 2015.

10. Hoyt D. Executive director's report: Looking forward. Bulletin of the American College of Surgeons. April 8, 2015. Available at: https://www.facs. org/ /media/files/publications/bulletin/2015/15aprbull\%20\%20lowres.ashx. Accessed February 2, 2016.

11. American Board of Thoracic Surgery. Definition of thoracic surgery. Available at: https://www.abts.org/root/home/definition-of-thoracic-surgery.aspx. Accessed February 2, 2016

12. American Association of Critical Care Nurses. Initial CSC certification. Available at: http://www.aacn.org/wd/certifications/content/initial-csc-certification. pcms?menu=certification\#Initial_Eligibility_Requirements. Accessed October $15,2015$.

13. Astin F, Carroll DL, Ruppar T, Uchmanowicz I, Hinterbuchner L, Kletsiou E, et al. A core curriculum for the continuing professional development of nurses: developed by the Education Committee on behalf of the Council on Cardiovascular Nursing and Allied Professions of the ESC. Eur J Cardiovasc Nurs. 2015;14:190-7.

14. Surgical Critical Care Program Directors Society. Surgical critical care training curriculum. Available at: http://sccpds.org/wp-content/uploads/2013/01/TA_99_ 2_2010_06_07_ALAM_203917_SDC2a.pdf. Accessed October 15, 2015.

15. Sherif HM, Cohn LH. Certification in cardiothoracic surgical critical care [editorial]. J Thorac Cardiovasc Surg. 2014;147:1454-5.

16. Baumgartner WA, Calhoon JH, Shemin RJ, Allen MS. Critical care: American Board of Thoracic Surgery update. J Thorac Cardiovasc Surg. 2013;145:1448-9.

17. American Board of Thoracic Surgery. Cardiothoracic critical care statement. Available at: https://www.abts.org/root/home/critical-care.aspx. Accessed November 12, 2015.

18. Sherif HM. Developing a true Cardiothoracic surgeon: professionalism, regulation and the normalization of deviance. Bulletin of the Society for Cardiothoracic Surgery in Great Britain and Ireland. July 2014. Available at: http://www.scts. org/_userfiles/resources/635415439197129609_SCTS_0714_Bulletin_Final_ x1.pdf. Accessed November 12, 2015.

19. Joshi V. Out-of-hours intensive care unit cover by nurse practitioners: does this have a detrimental effect towards critical care exposure to the cardiothoracic trainee? Eur J Cardiothorac Surg. 2013;44:967.

20. Katz NM. It is time for certification in cardiothoracic critical care? J Thorac Cardiovasc Surg. 2013;145:1446-7.

21. Dannemiller KD, Jacobs RW. Changing the way organizations change: a revolution of common sense. J Appl Behav Sci. 1992;28:480-98.

22. Shemin RJ. Postgraduate experiential learning is essential for surgical maturation. J Thorac Cardiovasc Surg. 2015;150:1069-70.

Key Words: cardiothoracic surgical critical care, certification, professional regulation 